\title{
Performance Analysis of Corporate Feed Rectangular Patch Element and Circular Patch Element 4x2 Microstrip Array Antennas
}

\author{
Md. Tanvir Ishtaique-ul Huque ${ }^{1}$, Md. Al-Amin Chowdhury ${ }^{2}$, Md. Kamal Hosain ${ }^{3}$, Md. Shah Alam ${ }^{4}$ \\ ${ }^{1,2,3}$ Dept. of Electronics and Telecommunication Engineering, \\ ${ }^{4}$ Dept. of Electrical and Electronic Engineering, \\ Rajshahi University of Engineering \& Technology, Rajshahi-6204, Bangladesh.
}

\begin{abstract}
This paper present simple, slim, low cost and high gain circular patch and rectangular patch microstrip array antenna, with the details steps of design process, operate in $\mathrm{X}$ band $(8 \mathrm{GHz}$ to $12 \mathrm{GHz}$ ) and it provides a mean to choose the effective one based on the performance analysis of both of these array antennas. The method of analysis, design and development of these array antennas are explained completely here and analyses are carried out for $4 \times 2$ arrays. The simulation has been performed by using commercially available antenna simulator, SONNET version V12.56, to compute the current distribution, return loss response and radiation pattern. The proposed antennas are designed by using Taconic TLY-5 dielectric substrate with permittivity, $\varepsilon_{\mathrm{r}}=\mathbf{2 . 2}$ and height, $\mathrm{h}=\mathbf{1 . 5 8 8} \mathrm{mm}$. In all cases we get return losses in the range $-4.96 \mathrm{~dB}$ to $-25.21 \mathrm{~dB}$ at frequencies around $10 \mathrm{GHz}$. The gain of these antennas as simulated are found above $6 \mathrm{~dB}$ and side lobe label is maintained lower than main lobe. Operating frequency of these antennas is $10 \mathrm{GHz}$ so these antennas are suitable for $\mathrm{X}$-band application.
\end{abstract}

Keywords- microstrip array antenna; rectangular patch; return loss; X band; circular patch.

\section{INTRODUCTION}

The term "Microstrip" comes because the thickness of this metallic strip is in micro-meter range. Microstrip patch antennas are popular, because they have some advantages due to their conformal and simple planar structure. They allow all the advantages of printed-circuit technology. A vast number of papers are available on the investigation of various aspects of microstrip antennas $[1,5,6,7,8,12,13]$. The key features of a microstrip antenna are relative ease of construction, light weight, low cost and either conformability to the mounting surface or, at least, an extremely thin protrusion from the surface. These criteria make it popular in the field of satellite and radar communication system. Different Radar systems such as synthetic aperture radar (SAR), remote sensing radars, shuttle imaging radar and other wireless communication systems operate in $\mathrm{L}, \mathrm{Ku}, \mathrm{C}$ and $\mathrm{X}$ bands $[11,12,14,15]$. Microstrip antennas are the first choice for this high frequency band such as X-band due to its light weight, low cost, and robustness. In this paper the designed microstrip antennas are also best suited for $\mathrm{X}$ band applications. The extended AM broadcast band or simply " $\mathrm{X}$ band" is a segment of the microwave radio region of the electromagnetic spectrum. Xband radar frequency sub-bands are used in civil, military and government institutions for weather monitoring, air traffic control, maritime vessel traffic control, defense tracking, and vehicle speed detection for law enforcement. In radar engineering, its frequency range is specified by the IEEE at 8.0 to $12.0 \mathrm{GHz}$. $\mathrm{X}$ band is used in radar applications including continuous-wave, pulsed, single-polarization, dualpolarization, synthetic aperture radar, and phased arrays. In Ireland, Libya, Saudi Arabia and Canada, the X band 10.15 to 10.7 segment is used for terrestrial broadband. Portions of the $\mathrm{X}$ band are assigned by the International Telecommunications Union (ITU) exclusively for deep space telecommunications. The primary user of this allocation is the American NASA Deep Space Network (DSN) [16].

Microstrip patch elements are available in various configuration. But the most common is the rectangular patch element and after the rectangular patch element the next most well known configuration is the circular patch element. This paper presents the design procedure, characteristic and the corresponding performance analysis of both the rectangular and circular patch microstrip array antennas and provides a mean to choose the effective one based on their performance parameters to get the efficient radiation efficiency. In this paper we have also investigated the performance of corporate feed array in case of both the rectangular patch element and circular patch element, because it provides better directivity as well as radiation efficiency and reduce the beam fluctuations over a band of frequencies compared to the series feed array $[5,9]$. Here all of these antennas are designed to support 10 $\mathrm{GHz}$ operating frequency and their corresponding simulations have been done by using the SONNET version V12.56 simulator. The proposed antennas are designed by using Taconic TLY-5 dielectric substrate with permittivity, $\varepsilon_{r}=2.2$ and height, $\mathrm{h}=1.588 \mathrm{~mm}$. These designed antennas are promising to be a good candidate for the $\mathrm{X}$-band wireless applications due to the simplicity in structure, ease of fabrication and high gain and high efficiency.

\section{Microstrip ANTENNA DESIGN}

Microstrip patch antennas consist of very thin metallic strip (patch) placed on ground plane where the thickness of the 
metallic strip is restricted by $\mathrm{t}<<\lambda_{0}$ and the height is restricted by $0.0003 \lambda_{0} \leq \mathrm{h} \leq .05 \lambda_{0}[2,5]$. The microstrip patch is designed so that its radiation pattern maximum is normal to the patch. For a rectangular patch, the length $\mathrm{L}$ of the element is usually $\lambda_{0} / 3<\mathrm{L}<\lambda_{0} / 2$. There are numerous substrates that can be used for the design of microstrip antennas and their dielectric constants are usually in the range of $2.2 \leq \varepsilon_{\mathrm{r}} \leq 12$. To implement the microstrip antennas usually Fr-4 $\left(\varepsilon_{\mathrm{r}}=4.9\right)$, Rogers TMM 4( $\left.\varepsilon_{\mathrm{r}}=4.5\right)$, Taconic TLY-5 $\left(\varepsilon_{\mathrm{r}}=2.2\right)$, Alumina $(96 \%)\left(\varepsilon_{\mathrm{r}}=9.4\right)$, Teflon(PTFE) $\left(\varepsilon_{\mathrm{r}}=2.08\right)$, Arlon AD $5\left(\varepsilon_{\mathrm{r}}=\right.$ 5.1) dielectric materials are used as the substrate $[1,2,5,10]$.

The Performance of the microstrip antenna depends on its dimension. Depending on the dimension the operating frequency, radiation efficiency, directivity, return loss and other related parameters are also influenced [3]. Here, in this paper, the investigation is made on two types of microstrip patch elements. They are

- Rectangular patch element

- Circular patch element.

\section{A. Rectangular Patch Element}

For an efficient radiation a practical width of the Rectangular patch element becomes $[2,3,5]$

$$
w=\frac{1}{2 f_{r} \sqrt{\mu_{\circ} \varepsilon_{\circ}}} \times \sqrt{\frac{2}{\varepsilon_{r}+1}}
$$

And the length of the antenna becomes [2, 3, 5]

$$
L=\frac{1}{2 f_{r \sqrt{\varepsilon_{e f f}}} \sqrt{\varepsilon_{\mathrm{O}} \mu_{\mathrm{O}}}}-2 \Delta L
$$

Where,

$$
\Delta L=0.41 h \frac{\varepsilon_{\text {eff }}+0.3}{\varepsilon_{\text {eff }}-0.258} * \frac{\left(\frac{w}{h}+0.264\right)}{\left(\frac{w}{h}+0.8\right)}
$$

And

$$
\varepsilon_{e f f}=\frac{\varepsilon_{r}+1}{2}+\frac{\varepsilon_{r}-1}{2 \sqrt{1+12 \frac{h}{w}}}
$$

Where, $\lambda$ is the wave length, $f_{\mathrm{r}}$ (in $\mathrm{Hz}$ ) is the resonant frequency, $L$ and $W$ are the length and width of the patch element, in $\mathrm{cm}$, respectively and $\varepsilon_{r}$ is the relative dielectric constant. In the following Fig. 1, the antenna has been designed to cover specific $10 \mathrm{GHz}$ operating frequency where the antenna dimension is in $\mathrm{mm}$ range and the quarter wavelength transformer method $[2,5]$ is used to match the impedance of the patch element with the transmission line.

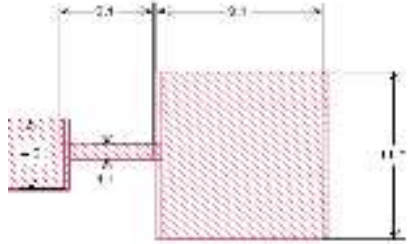

Figure 1. Single element Rectangular microstrip patch antenna.

\section{B. Circular Patch Element}

Other than the rectangular patch, the next most popular configuration is the circular patch or disk. For rectangular patch elements there are two degrees of freedom to control whereas for the circular patch elements there is one degree of freedom to control. Thus it is more convenient to design as well as to control the radiation pattern of the circular patch element.

From $[12,14]$ the first order approximation of the physical radius of the circular patch element becomes.

$$
a=\frac{F}{\sqrt{\left\{1+\frac{2 h}{\pi \in_{r} F}\left[\ln \left(\frac{\pi F}{2 h}\right)+1.7726\right]\right\}}}
$$

Where

$$
F=\frac{8.791 \times 10^{9}}{f_{r} \sqrt{\epsilon_{r}}}
$$

Thus the effective area of the circular patch element is given by [12]

$$
A_{e f f}=\pi a^{2}\left\{1+\frac{2 h}{\pi \in_{r} F}\left[\ln \left(\frac{\pi F}{2 h}\right)+1.7726\right]\right\}
$$

Where, $f_{r}$ (in $\mathrm{Hz}$ ) is the resonant frequency, $\mathrm{h}($ in $\mathrm{cm}$ ) is the thickness of the substrate, $a$ is the effective radius of the circular patch element and $\varepsilon_{r}$ is the relative dielectric constant.

In the following Fig. 2, the antenna has been designed to cover specific $10 \mathrm{GHz}$ operating frequency where the antenna dimension is in $\mathrm{mm}$ range and the quarter wavelength transformer method $[2,5]$ is used to match the impedance of the patch element with the transmission line.

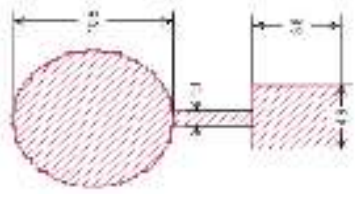

Figure 2. Single element circular microstrip patch antenna.

\section{MicRostriP ARRAY ANTENNA DESIGN}

Microstrip antennas are used not only as single element but also very popular in arrays. Microstrip arrays radiate efficiently only over a narrow band of frequencies and they can't operate at the high power levels of waveguide, coaxial line, or even stripline [1]. Antenna arrays are used to scan the beam of an antenna system, to increase the directivity and perform various other functions which would be difficult with any one single element. In the microstrip array, elements can be fed by a single line or by multiple lines in a feed network arrangement. Based on their feeding method $[2,5]$ the array is classified as

- $\quad$ Series feed network 
- Corporate feed network

Series-feed microstrip array is formed by interconnecting all the elements with high impedance transmission line and feeding the power at the first element. Because the feed arrangement is compact the line losses associated with this type of array are lower than those of the corporate-feed type [5]. The main limitation in series-feed arrays is the large variation of the impedance and beam-pointing direction over a band of frequencies [5].

The corporate-feed network is used to provide power splits of $2 n$ (i.e. $n=2$; 4 ; 8 ; 16; etc.). This is accomplished by using either tapered lines or using quarter wavelength impedance transformers $[5,6]$. In this paper the patch elements are connected by using the quarter wavelength impedance transformer method.

Corporate-feed arrays are general and versatile. This method has more control of the feed of each element and is ideal for scanning phased arrays, multiband arrays. Thus it provides better directivity as well as radiation efficiency and reduce the beam fluctuations over a band of frequencies compared to the series feed array [5,9]. The phase of each element can be controlled by using phase shifters while amplitude can be adjusted using either amplifiers or attenuators $[2,8]$.

In this paper we have investigated the performance of corporate feed array in case of both the rectangular patch element and circular patch element.

\section{A. Rectangular Patch Microstrip Array}

In this paper we have designed the 8-elements rectangular patch Microstrip array antenna, as shown in Fig. 3, to cover 10 $\mathrm{GHz}$ operating frequency. Here the power is fed to the antenna by using the Microstrip transmission line method[2, 3] and the patch elements are matched together as well as with the transmission line with the quarter wavelength transformer method for the maximum power transmission.

The radiated field of the $E$-plane for a single element rectangular patch can be expressed by using the following formula $[2,10]$.

$$
E=j \frac{k_{0} W V_{0} e^{-j k_{0} r}}{r \pi}\left\{\frac{\sin \left(\frac{k_{0} h}{2} \cos \varphi\right)}{\frac{k_{0} h}{2} \cos \varphi}\right\} \cos \left(\frac{k_{0} L_{e}}{2} \sin \varphi\right)
$$

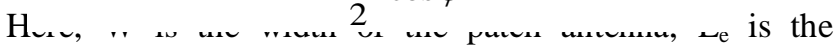
extended length, $\mathrm{V}_{0}=\mathrm{hE}_{0}$ is the voltage across radiating slot of the patch, $h$ is the substrate height, $K_{0}=2 \pi / \lambda$ and $r$ is the far field distance from the antenna.

The array factor as given in $[4,8]$ as

$$
F A=\frac{\sin ^{2}\left(N \pi\left(d_{x} / \lambda\right) \sin \theta\right)}{N^{2} \sin ^{2}\left(\pi\left(d_{x} / \lambda\right) \sin \theta\right)}
$$

Here, $d_{x}$ is the element spacing and $\mathrm{N}$ is the number of elements. Combining array factor and element voltage radiation pattern we get the total element normalized power radiation pattern $[2,4,5]$ that is

$$
20 \log (|E / F A|)
$$

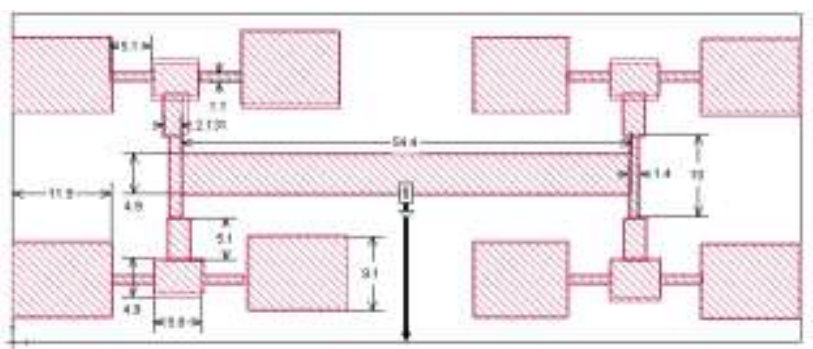

Figure 3. 8-elements corporate-feed rectangular microstrip array antenna.

\section{B. Circular Patch Microstrip Array}

Here the 8-elements circular patch Microstrip array antenna, as shown in Fig. 4, is designed to operate at $10 \mathrm{GHz}$ frequency and similar to the previous one the power is fed to the antenna by using the Microstrip transmission line method and the patch elements are matched together as well as with the transmission line with the quarter wavelength transformer method for the maximum power transmission.

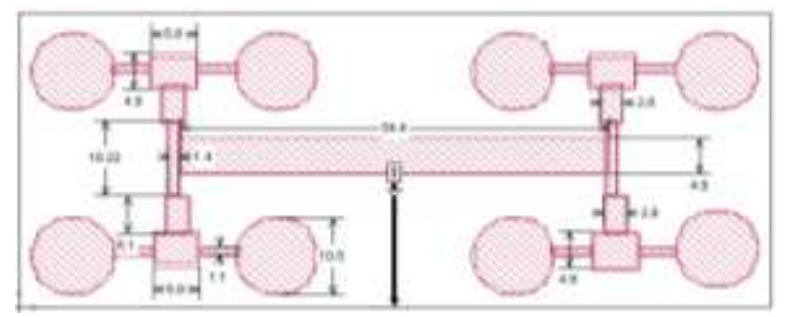

Figure 4. 8-elements corporate-feed circular microstrip array antenna.

The radiated field of the $E$-plane for a single element circular patch can be expressed by using the following formula $[2,5]$.

$$
E=-j V_{0} \frac{a k_{0} e^{-j k_{0} r}}{2 r} \cos \phi J_{1}^{\prime}\left(k_{0} a \sin \theta\right)
$$

Here, $\theta$ is the beam pointing angle measured from the broadside direction, $\mathrm{V}_{0}=\mathrm{hE}_{0}$ is the voltage across radiating slot of the patch, $\mathrm{K}_{0}=2 \pi / \lambda, \mathrm{J}_{1}$ is the Bessel function of first order and $\mathrm{r}$ is the far field distance from the antenna. The array factor as given in [14] as

$$
A F=A_{O} \frac{\sin \left(\frac{N \psi}{2}\right)}{N \sin \left(\frac{\psi}{2}\right)}
$$

Where

$$
\begin{gathered}
\psi=\alpha+\beta d \sin (\theta) \cos (\varphi) \\
\beta d=\left(\frac{2 \pi}{\lambda}\right) S
\end{gathered}
$$

Here, $\alpha$ is the phase difference between elements, $\mathrm{N}$ is the number of array elements and $\mathrm{S}$ is the spacing between circular patch elements. Now we can get the normalized power radiation pattern by combining the element radiation pattern and array factor [5]. 


\section{SimUlATION RESUlT \& DISCUSSION}

\section{A. Rectangular Microstrip Array Antenna Parameters}

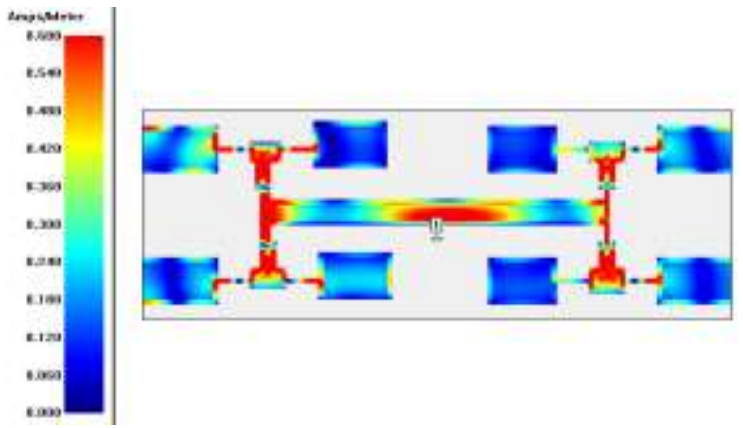

Figure 5. Current distribution of 8-elements rectangular microstrip array antenna.

In this paper, it is considered that the substrate permittivity of the antenna is $\varepsilon_{\mathrm{r}}=2.2$ (Taconic TLY-5), height is 1.588 $\mathrm{mm}$ and resonance frequency of the antenna is $10 \mathrm{GHz}$. After simulation, as shown in Fig. 6, we found that, return loss is $25.21 \mathrm{~dB}$ at $10 \mathrm{GHz}$ and it is maximum.

The simulated gain of the antenna, according to Fig. 7, is found around $6 \mathrm{~dB}$ at $\theta=0^{0}, \varphi=0^{0}$ at the operating frequency 10 GHz. Fig. 8 shows that the HPBW and the FNBW for this simulated antenna are in the range $70^{\circ} \& 142.10^{\circ}$ respectively.

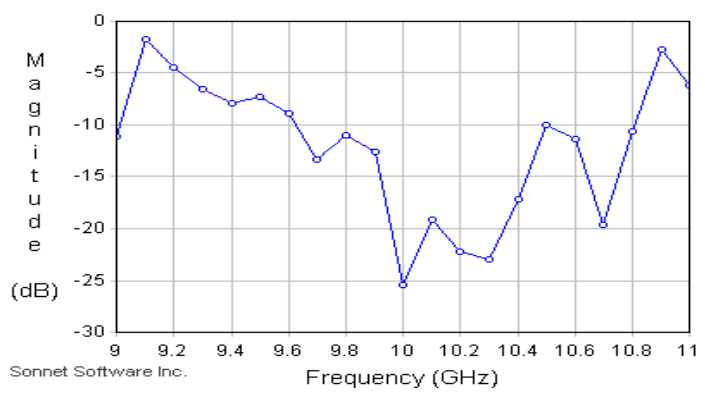

Figure 6. Return loss of the 8-elements rectangular microstrip array.

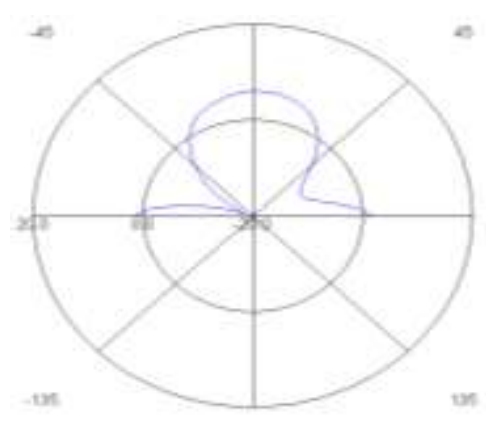

Figure 7. Radiation (Polar plot) pattern of the 8-elements rectangular microstrip array antenna.

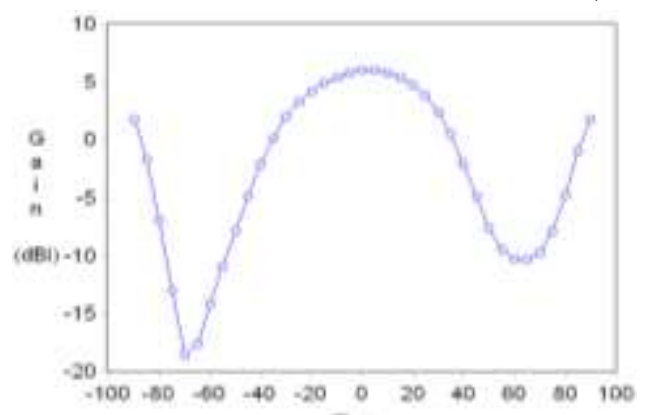

Figure 8. Radiation (Rectangular plot) pattern of the 8-elements rectangular microstrip array antenna.

\section{B. Circular Microstrip Array Antenna Parameters}

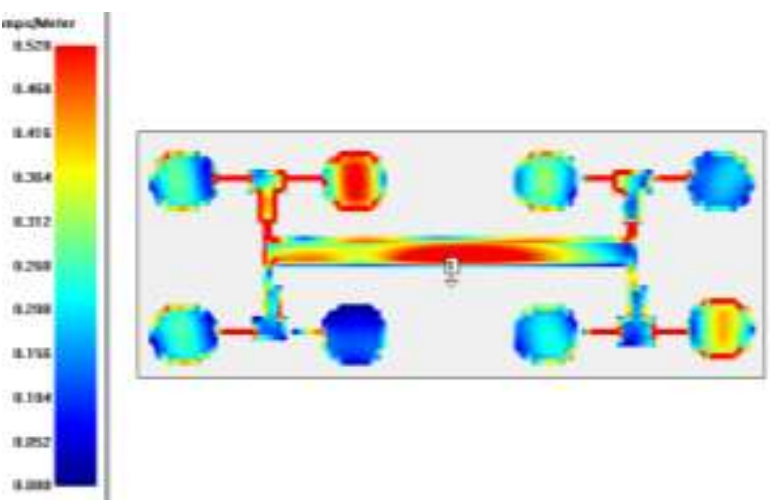

Figure 9. Current distribution of the 8-elements circular microstrip array antenna.

Here, the substrate permittivity of the antenna is 2.2 (Taconic TLY-5), height is $1.588 \mathrm{~mm}$ and resonance frequency of the antenna is $10 \mathrm{GHz}$. After simulation, as shown in Fig. 10, we found that, return loss is $-4.96 \mathrm{~dB}$ at 10 $\mathrm{GHz}$ and it is maximum that is $-6.91 \mathrm{~dB}$ at $9.8 \mathrm{GHz}$ operating frequency. The simulated gain of the antenna, according to Fig. 11, is found around $7.21 \mathrm{~dB}$ at $\theta=0^{0}, \varphi=0^{0}$ for the operating frequency $10 \mathrm{GHz}$.

Fig. 12 shows that the HPBW and the FNBW for this simulated antenna are in the range $89^{\circ}$ and $130^{\circ}$ respectively and Fig. 9 gives us the concept of current distribution of this array antenna which states that current density at each element of circular array antenna is much higher than that of the rectangular one as shown in Fig. 5.

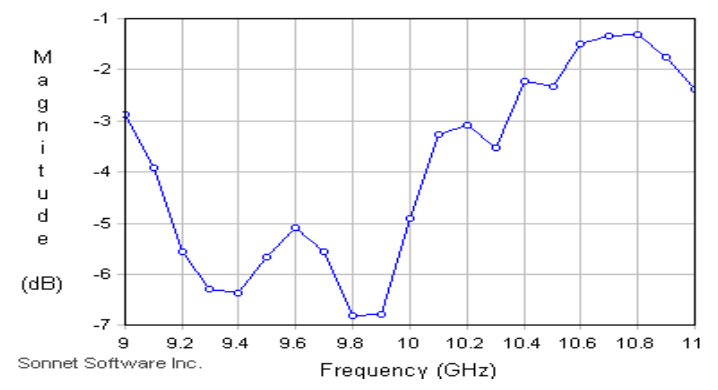

Figure 10. Return loss of the 8-elements circular microstrip array antenna. 


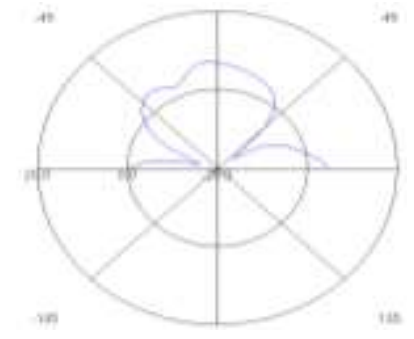

Figure 11. Radiation (polar plot) pattern of the 8-elements circular microstrip array antenna.

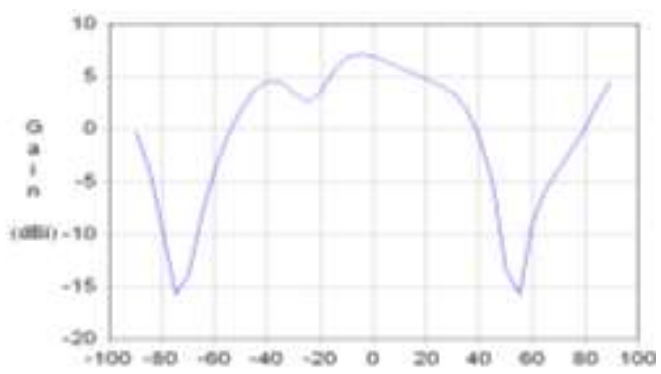

Figure 12. Radiation (rectangular plot) pattern of the 8-elements circular microstrip array antenna.

\section{Comparison Between These two Array Antennas}

After observing the performance analysis of both of these array antennas, it is convenient to say that the circular patch microstrip array antenna provides better performance than the rectangular patch Microstrip array antenna. Circular microstrip array antenna has the higher directive gain as well as the narrow beam width which seem to be a suitable criteria to design a transceiver antenna. Moreover its one degree of freedom to control reduce the design complexities. It also shows a remarkable achievements in case of current distribution. The current density for the rectangular microstrip array antenna, as shown in Fig. 5, at each patch element is not less than $0.12 \mathrm{amp} / \mathrm{m}$ and it is maximum up to $0.356 \mathrm{amp} / \mathrm{m}$. Whereas the current density for the circular microstrip array antenna, as shown in Fig. 9, at each patch element is not less than $0.156 \mathrm{amp} / \mathrm{m}$ and it is maximum up to $0.52 \mathrm{amp} / \mathrm{m}$. Thus the circular Microstrip array occupies lower transmission loss and it's the higher current density at each element provides better radiation efficiency than the rectangular microstrip array.

TABLE I. PERFORMANCE ANALYSIS BETWEEN RECTANGULAR AND CIRCULAR MICROSTRIP ARRAY ANTENNAS

\begin{tabular}{|c|c|c|}
\hline \multirow{2}{*}{$\begin{array}{c}\text { Performance } \\
\text { Parameter }\end{array}$} & \multicolumn{2}{|c|}{ Feeding Types } \\
\cline { 2 - 3 } & $\begin{array}{c}\text { Rectangular } \\
(4 \times 2) \text { array }\end{array}$ & $\begin{array}{c}\text { Circular } \\
(4 \times 2) \text { array }\end{array}$ \\
\hline $\begin{array}{c}\text { Physical } \\
\left.\text { area(mm }{ }^{2}\right)\end{array}$ & $95.6 \times 34.2$ & $92.8 \times 35.82$ \\
\hline $\begin{array}{c}\text { Degree of } \\
\text { freedom to control }\end{array}$ & Two & One \\
\hline FNBW & $142.10^{0}$ & $130^{0}$ \\
\hline $\begin{array}{c}\text { Simulated } \\
\text { gain(dB) }\end{array}$ & Around 6 & 7.21 \\
\hline
\end{tabular}

\begin{tabular}{|c|c|c|}
\hline $\begin{array}{c}\text { Transmission } \\
\text { line loss }\end{array}$ & Higher & Lower \\
\hline Return $\operatorname{loss}(\mathrm{dB})$ & -25.21 & -4.96 \\
\hline
\end{tabular}

\section{CONCLUSION}

The unique feature of this microstrip antenna is its simplicity to get higher performance. In many applications basically in radar and satellite communication, it is necessary to design antennas with very high directive characteristics to meet the demand of long distance communication and the most common configuration to satisfy this demand is the array form of the microstrip antenna. After the rectangular patch the next most popular configuration is the circular patch and in our investigation, comparing the circular patch microstrip array antenna with the rectangular one, we have found that the circular microstrip array has some advantages such as small dimensions, light weight, higher directivity, higher current density and easy manufacturing. The physical area of the circular patch is $16 \%$ less than that of the rectangular patch [5].

Here designed array antennas covers $10 \mathrm{GHz}$ operating frequency and it would also be possible to design the bands, operating any other system such as in WLAN, WiMax, WBAN or other wireless systems, by changing the dimension of the patch element. In future, we can investigate the spiral elements which seems to have more radiation efficiency for both the series feed and corporate feed networks and at the same time we can merge two different patch elements operating at two or more different frequencies by using quarter wavelength transformer method within an array network configuration to get multiband support.

\section{REFERENCES}

[1] R. J. Mailloux, J. F. Mcllvenna, N. P. Kernweis, "Microstrip array technology", IEEE Trans. Antenna Propagation Magazine, Vol. 29, No. 1, pp. 25-27, 1981.

[2] C. A. Balanis, Antenna Engineering, $2^{\text {nd }}$ ed., Willey, 1982.

[3] T. A. Millikgan, Modern Antenna Design, $2^{\text {nd }}$ ed. , IEEE Press, John Wiley \& Sons inc., 2007.

[4] M. I. Skolnik, Introduction to RADAR System, $3^{\text {rd }}$ ed., McGraw Hill Higher Education, 2000.

[5] R. Garg, P. Bhartia, I. Bahl, A. Ittipiboon, Microstrip Antenna Design Handbook, Artech House inc., 2001.

[6] R. J. Milloux, Electronically Scanned Arrays, Morgan \& Claypool, 2007.

[7] W. L. Stutzman, "Estimating directivity and gain of antennas", IEEE Antennas and Propagation Magazine, Vol. 40, No. 4,pp 7-11, August, 1998.

[8] H. J. Visser, Array and Phased Array Antenna Basics, John Wiley \& Sons Ltd., 2005.

[9] Muhammad Mahfuzul Alam, Md. Mustafizur Rahman Sonchoy, and Md. Osman Goni, "Design and Performance Analysis of Microstrip Array Antenna", Progress In Electromagnetic Research Symposium Proceedings, Moscow, Russia, August 18-21, 2009.

[10] Md. Shihabul Islam and Md. Tanvir Ishtaique-ul Huque, "Design and Performance Analysis of Microstrip Array Antenna", B.Sc. 
Engineering thesis, Dept. of ETE, Rajshahi University Of Engineering \& Technology(RUET), Rajshahi, Bangladesh, April, 2010.

[11] Gi-cho Kang, Hak-young Lee, Jong-kyu Kim, Myun-joo Park,"Kuband High Efficiency Antenna with Corporate-Series-Fed Microstrip Array", IEEE Antennas and Propagation Society International Symposium, 2003.

[12] T. F. Lai, Wan Nor Liza Mahadi, Norhayatision, "Circular Patch Microstrip Array Antenna for KU-band", World Academy of Science, Engineering and Technology, vol. 48, pp. 298-302, 2008.

[13] K. Shambavi, C. Z. Alex, T. N. P. Krishna, "Design and Analysis of High Gain Milimeter Wave Microstrip Antenna Array for Analysis of High Gain Millimeter Wave Microstrip Anteanna Array for Wireless Application", Journal of Applied Theoretical and Information Technology(JATIT), 2009.

[14] Asghar Keshtkar, Ahmed Keshtkar and A. R. Dastkhosh, "Circular Microstrip Patch Array Antenna for C-Band Altimeter System", International Journal of Antenna and Propagation, article ID 389418, doi:10.1155/2008/389418, November, 2007.

[15] M. F. Islam, M. A. Mohd. Ali, B. Y. Majlis and N. Misran, "Dual Band Microstrip Patch Antenna for Sar Applications", Australian Journal of Basic and Applied Sciences, 4(10): 4585- 4591, 2010.

[16] http://en.wikipedia.org/wiki/X_band

\section{AUTHORS PROFILE}

Md. Tanvir Ishtaique-ul Huque was born in 1988 in Bangladesh. He received his B.Sc. Engineering degree from the Rajshahi University of
Engineering \& Technology (RUET) in 2010. Now he is working as a part time teacher in the Dept. of Electronics and Telecommunication Engineering of RUET. His research interests include the antenna application of the wireless body area network(WBAN) and next generation wireless communication system.

Md. Al-Amin Chowdhury was born in 1988 in Bangladesh. he has completed his B.Sc. in Electronic and Telecommunicaton Engineering from Rajshahi University of Engineering \& Technology(RUET) in 2010. He has keen interest to research on the optical fiber, different types of antennas. He wants to do his further study in USA on the communication field. World is becoming closer and closer due to the remarkable achievements in the communication field. He wants to receive the sound and proper knowledge in communication field so that he can contribute to the next generation demands in the communication sectors.

Md. kamal Hosain was born in 1982 in Bangladesh. He received his B.Sc. Engineering degree from the khulna University of Engineering \& Technology(KUET) in 2001 and now he working as a Lecturer in the Dept. of Electronics and Telecommunication Engineering(ETE) of RUET. His research interests include the antenna and its application on the biomedical devices.

Md. Shah Alam was born in Rangpur, Bangladesh, on June 24, 1982. He received the B.Sc. degree in Electrical and Electronic Engineering from Rajshahi University of Engineering \& Technology, Rajshahi, Bangladesh, in 2006. He is going to be completed his M.SC degree from the same institution on July, 2011. From 2007 to 2009 , he was a Lecturer with the Rajshahi University of Engineering \& Technology, Rajshahi, Bangladesh and currently he is working there as an Assistant Professor. His research interests involve Electromagnetic and Nanotechnology. 